\title{
The use of exhaled nitric oxide and peak expiratory flow to demonstrate improved breathability and antimicrobial properties of novel face mask made with sustainable filter paper and Folium Plectranthii amboinicii oil: additional option for mask shortage during COVID-19 pandemic
}

\author{
Sy Duong-Quy, ${ }^{1,2,3 *}$ Xuan Ngo-Minh, ${ }^{3 *}$ Trinh Tang-Le-Quynh, ${ }^{1}$ Tram Tang-Thi-Thao, ${ }^{1}$ Bao Nguyen-Quoc, ${ }^{1}$ \\ Khiet Le-Quang, ${ }^{1}$ Dinh Tran-Thanh, ${ }^{1}$ Nhu Doan-Thi-Quynh, ${ }^{1}$ Ethan Canty, ${ }^{2}$ Toan Do, ${ }^{2}$ Timothy Craig ${ }^{2}$ \\ ${ }^{1}$ Medical-Biological Research Center, Lamdong Medical College, Da Lat city, Vietnam \\ ${ }^{2}$ Division of Immuno-Allergology, Hershey Medical Center, Penn State Medical College, Hershey, PA, USA \\ ${ }^{3}$ Pham Ngoc Thach Medical University, Ho Chi Minh city, Vietnam \\ *Co-first author
}

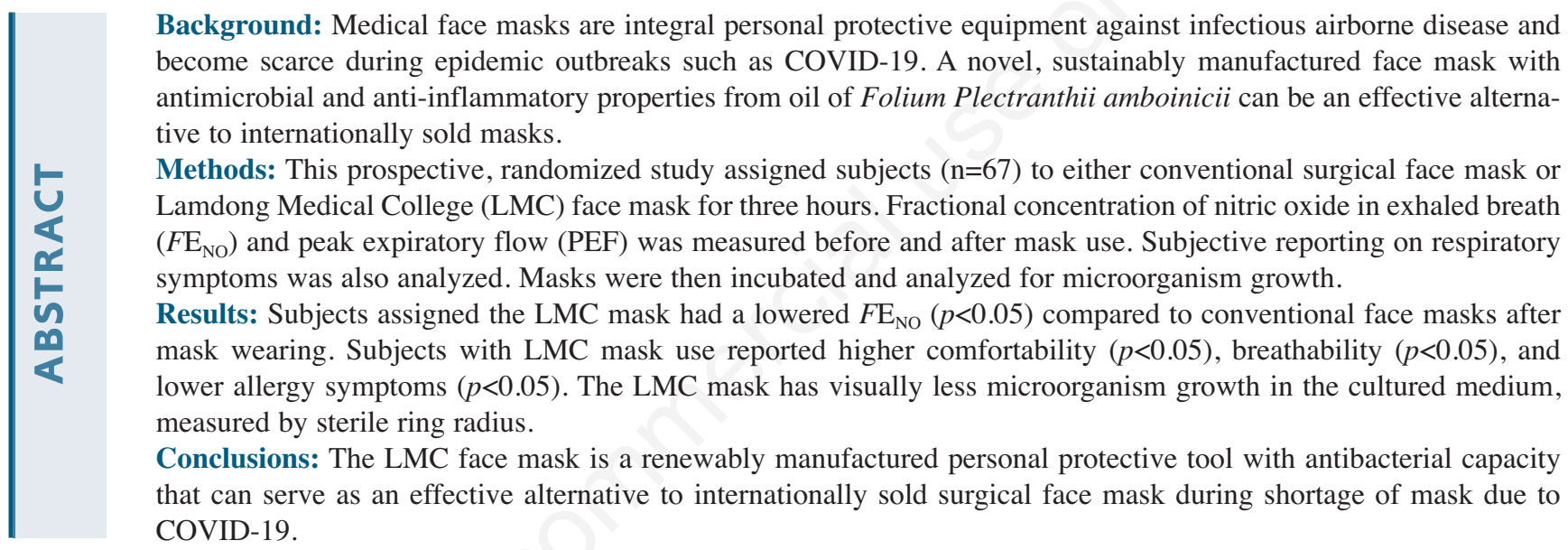

Background: Medical face masks are integral personal protective equipment against infectious airborne disease and become scarce during epidemic outbreaks such as COVID-19. A novel, sustainably manufactured face mask with antimicrobial and anti-inflammatory properties from oil of Folium Plectranthii amboinicii can be an effective alternaive to internationally sold masks. $(F E)$ and peak expiratictory symptoms was also analyzed. Masks were then incubated and analyzed for microorganism growth.

Results: Subjects assigned the LMC mask had a lowered $F \mathrm{E}_{\mathrm{NO}}(p<0.05)$ compared to conventional face masks after mask wearing. Subjects with LMC mask use reported higher comfortability $(p<0.05)$, breathability $(p<0.05)$, and lower allergy symptoms $(p<0.05)$. The LMC mask has visually less microorganism growth in the cultured medium, measured by sterile ring radius.

that can serve as an effective alternative to internationally sold COVID-19.
\end{abstract}

Key words: Filter paper mask; Folium Plectranthii amboinicii; COVID-19; pandemic; mask shortage.

Correspondence: Pr. Sy Duong-Quy, Director of Clinical Research Center and Lamdong Medical College, 16 Ngo Quyen, Dalat city, Vietnam. Tel: +84.918413813 - Fax: +84.2633.815000. E-mail: sduongquy.jfvp@gmail.com

Contributions: All the authors conceived and designed the study; SDQ, XNM, TTLQ, TTTT, data acquisition, interpretation and analysis; SDQ, NQ, KLQ, DTT, NDTQ, DT, CE, CT, work drafting, review \& editing; SDQ, XNM, NDTQ, DT, CE, CT, approved the submitted version and agreed both to be personally accountable for the author's own contributions and to ensure that questions related to the accuracy and integrity of any part of the work are appropriately investigated, resolved, and the resolution documented in the literature.

Conflict of interest: The authors declare that they have no competing interests.

Availability of data and materials: The datasets used and/or analyzed during the current study are available from the corresponding author on reasonable request.

Ethics approval and consent to participate: The study was realized in accordance with the Declaration of Helsinki, and the protocol was approved by the Ethics Committee of Lam Dong Medical College Institutional Review Board. All study subjects had signed Informed Consent approved by Institutional Review Board (IRB) of Lam Dong Medical College.

Consent for publication: Not applicable. 


\section{Introduction}

Medical face masks are commonly used in the prevention of infectious airborne diseases [1-3]. In epidemic outbreaks, such as COVID-19 pandemic, the scarcity of surgical masks presents a serious public health challenge to preventing transmission of infectious diseases in the healthcare environment [4]. China, which produced roughly $50 \%$ of the global supply of face masks, was also the epicenter of the COVID-19 outbreak. As the key supplier of face masks, this created a significant shortage throughout the world [4]. Furthermore, the increased demand for face masks caused extreme price hikes, which severely deterred people from purchasing them. This occurred even in countries not experiencing an outbreak of COVID-19. It is crucial for countries to have alternative means to produce effective, high quality face masks during an epidemic without needing to rely on the international supply of mask manufacturing resources. Face masks are generally made of non-renewable materials, such as plastic-based products, increasing global carbon emission and pollution. During infectious disease outbreaks, such as the 2019 outbreak of COVID-19, increased demand for plastic-based face masks also places a significant burden on the environment. Therefore, developing and manufacturing a face mask using sustainable materials, like filter paper, would be cleaner and safer for the environment. The masks have the potential to be manufactured in more countries, in a sustainable manner, which would improve the supply during epidemics while also reducing the impact of plastics in the environment. Folium Plectranthii amboinicii (Lour.) Speng (Lamiaceae), (syn. Colius ambionicus), or Mexican Mint oil, is a traditional Vietnamese medicinal plant commonly used to treat upper respiratory infections, bronchitis, and gastrointestinal infections [5-8]. Previous studies have demonstrated that the Plectranthii amboinicii leaf oil possesses antimicrobial and antioxidant properties [9-11]. The oil has antibacterial effects against Staphylococcus aureus, Escherichia coli and Bacillus subtilis and antifungal effect against Candida albicans [6,11]. However, other uses of the oil have not been explored or tested. At high concentration, the oil demonstrated antioxidant properties similar to butyl hydroxyl toluene (BTH) [6]. In many countries,
Plectranthii amboinicii's antimicrobial property is used to treat respiratory tract infections and gastroenterological illnesses and its antioxidant property is applied as a pain-killer and anti-anxiety agent [5-7]. The anti-inflammatory and antimicrobial properties of Plectranthii amboinicii leaf oil have not been explored in personal protective gear such as surgical face masks. However, the use of face mask infiltrated with the compound of antimicrobial property must be checked to assure its safety for users. Therefore, the comfortability with breathing and other respiratory side effects of the novel face mask after having worn it should be clarified by using the relevant and compatible tools. Fractional concentration of nitric oxide in exhaled breath $\left(F \mathrm{E}_{\mathrm{NO}}\right)$, a relevant inflammatory biomarker of respiratory system, has been used to measure the response of airways with allergens and other stimulants in breathing air [12]. Currently, $F \mathrm{E}_{\mathrm{NO}}$ is used largely in monitoring patients with asthma and airway hyperresponsiveness [13,14]. In these patients, the measurement of peak expiratory flow (PEF) is also recommended to evaluate the immediate progression of airway obstruction via the use of peak flow meter [15].

The aim of this study is to determine if a novel face mask, manufactured from locally-sourced, sustainable materials with antimicrobial and anti-inflammatory properties from the Plectranthii amboinicii plant oil, can serve as an effective alternative to current surgical face masks sold on the international market. In the present study, the comfortability and other side effects of the novel face mask after wearing were demonstrated by clinical symptoms, $F \mathrm{E}_{\mathrm{NO}}$, and PEF measurements.

\section{Materials and Methods}

\section{Materials}

The Lamdong Medical College (LMC) mask is made from qualified cellulose paper with four filter paper (two in external face $\left[1^{\text {st }}\right.$ and $2^{\text {nd }}$ layers $]$ or front layers and two in internal face $\left[6^{\text {th }}\right.$ and $7^{\text {th }}$ layers] or back layers) and two blotter papers [ $3^{\text {rd }}$ and $5^{\text {th }}$ layers] placed in the middle separated by one layer of water proof paper $\left[4^{\text {th }}\right.$ layer] (Figure 1). The $3^{\text {rd }}$ and $5^{\text {th }}$ blotter paper layers are placed in

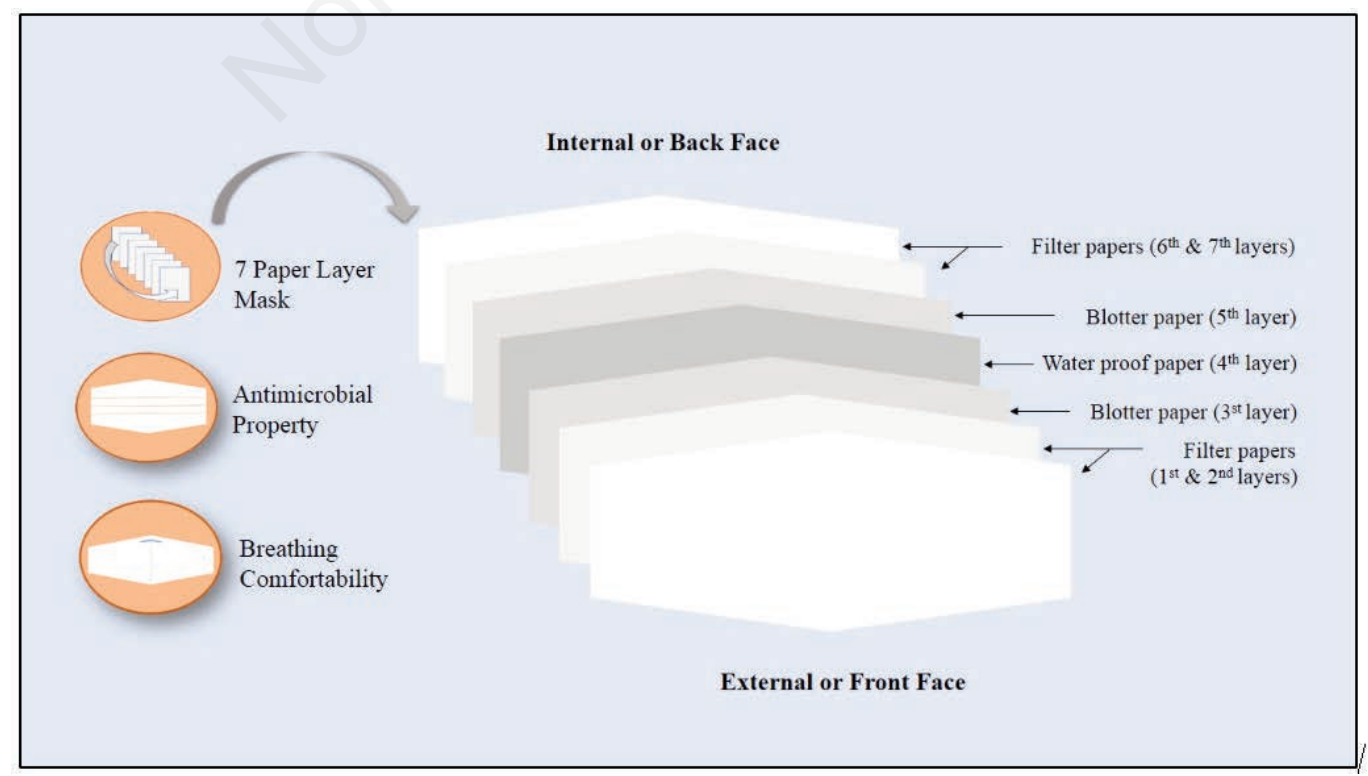

Figure 1. Detail structure of LMC face mask. LMC, Lamdong Medical College. 
external face which contains activated carbon, standardized BSI (Benzoic acid, Salicylic, and lode) solution of 5\%, and Plectranthii amboinicii plant oil extract of $0.5 \%$. In total, the LMC mask is made up of four layers of filter paper, two layers of blotter papers, and one layer of water proof paper (Figure 1). This mask has been qualified by the criteria of Directorate for Standards, Metrology and Quality of Vietnam. The conventional face mask used to compare the LMC mask is a four-layer activated carbon surgical mask.

\section{Study subjects}

The staff of local administrative colleges (Dalat, Vietnam) was eligible for this study after signing an Institutional Review BoardApproved consent form. The study was approved by the Ethic Council of Lamdong Medical (LMC2020.01.SRS, 15 ${ }^{\text {th }}$ January 2020). Subjects were informed that they could withdraw at any stage of the study.

\section{Inclusion criteria}

To be eligible for the study, subjects needed to be healthy, consenting adults ( $\geq 18$ years), without upper or lower respiratory acute symptoms or chronic diseases such as allergic rhinitis, rhinosinusitis, chronic bronchitis, asthma or chronic obstructive pulmonary disease (COPD).

\section{Exclusion criteria}

Adults with one of the following criteria were excluded from this study: active smoking; having respiratory symptoms (rhinorrhea, cough, respiratory difficulty, allergy, etc.); known respiratory allergy, smoker, alcohol drinker, or ingested caffeine the day of study; unable to perform exhaled nitric oxide (NO) and peak flow measurements; or being unable to obtain consent or absent during followup.

\section{Study design}

This was a prospective and randomized clinical study. After consenting to the study and providing demographic data, peak flow and exhaled NO measurements were obtained from each subject at inclusion. Subjects were then randomized to wear either the LMC mask or the conventional mask (GreetMed, ANJ International Corp., UK) with the same administrative activities. Subjects were asked subjective reporting on comfortability and symptoms of their assigned masks. Subjects remained in the same facility for three hours wearing their assigned masks and then repeated peak flow and exhaled NO measurements once the three hours were complete. In this duration, symptoms of discomfort, cough, allergic symptoms, rhinorrhea, or respiratory distress were continuously monitored. The masks of each subject were then collected for laboratory analysis. For each mask, the front and back layer of the mask were collected, trimmed, and cut into three pieces, yielding a total of six pieces. One piece from the front and back layer were separated into plate count agars. Each plate was placed into an incubator at $37^{\circ} \mathrm{C}$ for $24 \mathrm{~h}$ and bacterial growth was compared.

\section{Peak expiratory flow}

PEF was done by Peak - Flow Eolys (AstraZeneca, France) according to the manufacturer's instructions. Subjects were asked to provide three PEF measurements, and the highest value among the three measurements was used for data analysis.

\section{Exhaled nitric oxide measurements}

Fractional concentration of $\mathrm{NO}$ in exhaled breath $\left(F \mathrm{E}_{\mathrm{NO}}\right)$ was done by NObreath (Bedfront Scientis Ltd, Kent, England) according to manufacturer's instructions with expiratory air flows of $50 \mathrm{~mL} / \mathrm{second}$ for $F \mathrm{E}_{\mathrm{NO}}$. The $F \mathrm{E}_{\mathrm{NO}}$ was determined by measuring the room's $F \mathrm{E}_{\mathrm{NO}}$ level and subtracting this value from the subject's measured $F \mathrm{E}_{\mathrm{NO}}$ value. The use of portable device for
$F \mathrm{E}_{\mathrm{NO}}$ measurement was done as recommended previously [12]. The mean value of two correctly performed measures was used for analyses. $F \mathrm{E}_{\mathrm{NO}}$ levels were classified as recommended by the American Thoracic Society for adult ( $<25 \mathrm{ppb}$ : normal; 25-50 ppb: increased; $>50$ ppb: highly increased) [13].

\section{Subjective symptoms}

Subjects were asked subjective symptoms about the comfort of the mask they wore, symptoms of rhinorrhea, cough, allergic symptoms, or respiratory distress. These symptoms were monitored continuously while the subjects were wearing the masks.

\section{Biological activity testing}

Sabouraud dextrose, and MacConkey agars were used to assess bacterial growth of each face mask (LMC mask and conventional mask) before use and after use. Each agar was placed into an incubator set to $37^{\circ} \mathrm{C}$ for $24 \mathrm{~h}$. After the $24 \mathrm{~h}$, bacterial growth was compared for each piece using visual and diameter measurements of growth.

\section{Statistical analysis}

SPSS software 16.0 (Chicago, IL, USA) and Microsoft Excel were used to perform statistical analysis on all recorded data. Mean \pm SD was used to present categorical variables. $T$-test and ANOVA were used to differentiate between groups. Differences were significant at $p<0.05$ level and confidence interval $\geq 95 \%$.

\section{Results}

\section{Demographic and functional characteristics of study subjects}

From January $25^{\text {th }}$ to March $25^{\text {th }}, 2020,67$ adults who met the inclusion criteria were included in the study. The subjects were $32.8 \%$ males, had a mean age of $39.4 \pm 10.2$ years, mean height of $159.6 \pm 6.9 \mathrm{~cm}$, mean weight of $56.8 \pm 7.7 \mathrm{~kg}$, and mean BMI of

Table 1. Demographic and functional characteristics of study subjects.

Subject characteristics ( $n=67) \quad$ MeantsD or \% (n)

\section{Demographic characteristics}

$\begin{array}{lc}\text { Age, years } & 39.4 \pm 10.2 \\ \text { Male (female), \% } & 32.8(67.2) \\ \text { Height, cm } & 159.6 \pm 6.9 \\ \text { Weight, } \mathrm{kg} & 56.8 \pm 7.7 \\ \text { BMI, } \mathrm{kg} / \mathrm{m}^{2} & 26.4 \pm 2.9\end{array}$

\begin{tabular}{ll} 
Job title & \\
Administrative staff, \% (n) & $14.9(10 / 67)$ \\
Teacher, \% (n) & $65.7(44 / 67)$ \\
Other, \% (n) & $19.4(13 / 67)$ \\
\hline
\end{tabular}

\section{Comorbidity}

High blood pressure, \% (n)

$2.9(2 / 67)$

Arrhythmia or coronary disease, \% (n)

Diabetes, $\%$ (n)

Rheumatology, \% (n)

$1.5(1 / 67)$

Non, \% (n)

$2.9(2 / 67)$

$2.9(2 / 67)$

$89.8(60 / 67)$

\begin{tabular}{lc} 
Functional characteristics & \\
$\mathrm{PEF}, \mathrm{L} / \mathrm{min}$ & $431.7 \pm 92.2$ \\
$F \mathrm{E}_{\mathrm{NO}}, \mathrm{ppb}$ & $12.5 \pm 6.8$ \\
Mask wearing time, hours & $2.5 \pm 0.5$ \\
\hline
\end{tabular}

BMI, body mass index; PEF, peak expiratory flow; $F \mathrm{E}_{\mathrm{No}}$, fractional concentration of nitric oxide in exhaled breath; ppb, part per billion. 
$26.4 \pm 2.9 \mathrm{~kg} / \mathrm{m}^{2}$ (Table 1). The 67 study subjects were randomized into two groups (Group 1 with $n=34$, and Group 2 with $n=33$ ) with no significant demographic differences $(p>0.05)$ between the groups (Table 2). Group 1 subjects were assigned the LMC masks and Group 2 subjects were assigned conventional masks. The PEF and $F \mathrm{E}_{\mathrm{NO}}$ were obtained from Group 1 and Group 2 prior to wearing the assigned mask. Group $1(n=34)$ had a mean PEF of $430.3 \pm 85.2 \mathrm{~L} / \mathrm{min}$ and $F \mathrm{E}_{\mathrm{NO}}$ of $13.2 \pm 6.5 \mathrm{ppb}$. Group 2 $(n=33)$ had a mean PEF of $433 \pm 99.1 \mathrm{~L} / \mathrm{min}$ and $F \mathrm{E}_{\mathrm{NO}}$ of 11.8 7.0. Comparison of PEF $(p>0.05)$ and $F \mathrm{E}_{\mathrm{NO}}(p>0.05)$ between Group 1 and Group 2 demonstrated no significant difference (Figure $2 \mathrm{~A}, \mathrm{~B}$ ).

\section{Modification of PEF and $F E_{\mathrm{NO}}$ after mask use in each Group and between Group 1 and Group 2}

The results (Figures 2 and 3, Table 3) showed that there was no significant difference of PEF between before and after mask use for Group 1 and Group $2(430.3 \pm 85.2$ vs $435.5 \pm 76.9 \mathrm{~L} / \mathrm{min}$ and $433 \pm 99.1$ vs $428.2 \pm 104.6 \mathrm{~L} / \mathrm{min}$, respectively; Table 3). In Group 1, the level of $F \mathrm{E}_{\mathrm{NO}}$ after mask use was lower than that measured before mask use $(8.2 \pm 4.2$ vs $13.2 \pm 6.5, \mathrm{p}=0.01$; Table 3$)$. The level of $F \mathrm{E}_{\mathrm{NO}}$ in Group 2 after mask use was higher than that measured before mask use (12.3 \pm 7.4 vs $11.8 \pm 7.0 \mathrm{ppb}$; Table 3$)$ but there was no significant difference $(p>0.05)$.
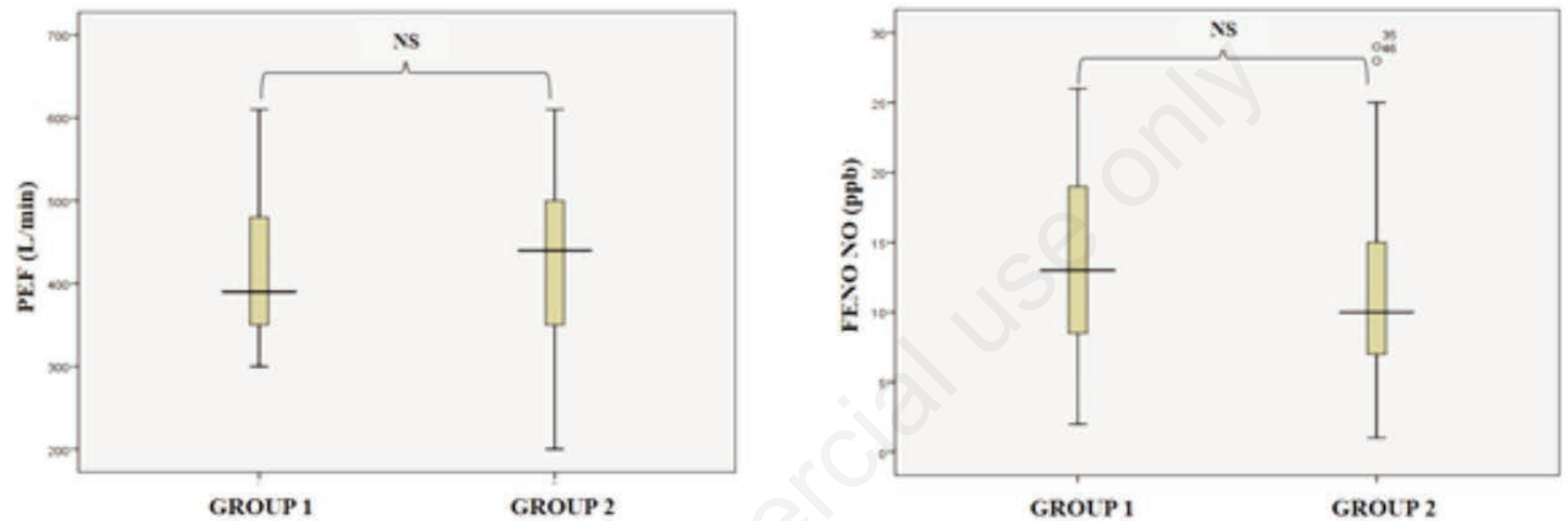

Figure 2. Comparison of PEF and $F \mathrm{E}_{\mathrm{NO}}$ between Group 1 and Group 2 before mask use. PEF, peak expiratory flow; $F E_{\mathrm{NO}}$, fractional concentration of nitric oxide in exhaled breath; ppb, part per billion; Group 1, LMC mask use; Group 2, conventional mask use.

Table 2. Characteristics of study subjects defined by Group 1 and Group 2.

\begin{tabular}{|c|c|c|c|}
\hline Characteristics of research subjects & Group $1(\mathrm{~N}=34)$ & Group $2(\mathrm{~N}=33)$ & $p$ \\
\hline \multicolumn{4}{|l|}{ Demographic characteristics } \\
\hline Age, years & $38.7 \pm 9.7$ & $40.1 \pm 10$ & NS \\
\hline Male (female), $\%$ & $32.8(67.2)$ & $36.3(63.7)$ & NS \\
\hline Height, $\mathrm{cm}$ & $160.1 \pm 6.3$ & $159 \pm 7.5$ & NS \\
\hline Weight, kg & $56.7 \pm 7.3$ & $57.0 \pm 8.1$ & NS \\
\hline BMI, $\mathrm{kg} / \mathrm{m}^{2}$ & $25.6 \pm 2.8$ & $27.0 \pm 2.8$ & NS \\
\hline \multicolumn{4}{|l|}{ Job title } \\
\hline Administrative staff, \% (n) & $14.7(5)$ & $15.2(5)$ & NS \\
\hline Teacher, \% (n) & $64.7(22)$ & $66.7(22)$ & NS \\
\hline Other, \% (n) & $20.6(7)$ & $18.1(6)$ & NS \\
\hline \multicolumn{4}{|l|}{ Comorbidity } \\
\hline High blood pressure, $\%(\mathrm{~N})$ & $2.9(1)$ & $3.0(1)$ & NS \\
\hline Arrhythmia or coronary disease, $\%$ (N) & $2.9(1)$ & $3.0(1)$ & NS \\
\hline Diabetes, $\%(\mathrm{~N})$ & $2.9(1)$ & $0.0(0)$ & NS \\
\hline Rheumatology, \% (N) & $2.9(1)$ & $3.0(1)$ & NS \\
\hline Non, $\%(\mathrm{~N})$ & 88.4 & 91.0 & NS \\
\hline \multicolumn{4}{|l|}{ Functional characteristics } \\
\hline Peak flow, L/min & $430.3 \pm 85.2$ & $433 \pm 99.1$ & NS \\
\hline$F \mathrm{E}_{\mathrm{NO}}, \mathrm{ppb}$ & $13.2 \pm 6.5$ & $11.8 \pm 7.0$ & NS \\
\hline Mask wearing time, hours & $2.8 \pm 0.2$ & $2.8 \pm 0.1$ & NS \\
\hline
\end{tabular}

BMI, body mass index; PEF, peak expiratory flow; $F \mathrm{E}_{\mathrm{NO}}$, fractional concentration of nitric oxide in exhaled breath; ppb, part per billion. Group 1, LMC mask use; Group 2, conventional mask use. 
The PEF and $F \mathrm{E}_{\mathrm{NO}}$ were obtained from group Group 1 (LMC masks) and Group 2 (conventional masks) after wearing assigned masks for three hours (Figure 3 A,B). Group $1(n=34)$ had a mean $\mathrm{PEF}$ of $435.5 \pm 76.9 \mathrm{~L} / \mathrm{min}$ and $F \mathrm{E}_{\mathrm{NO}}$ of $8.2 \pm 4.2 \mathrm{ppb}$. Group $2(\mathrm{~N}=$ 33 ) had a mean PEF of $428.2 \pm 104.6 \mathrm{~L} / \mathrm{min}$ and $F \mathrm{E}_{\mathrm{NO}}$ of $12.3 \pm 7.4$ ppb. Comparison of $F \mathrm{E}_{\mathrm{NO}}$ between Group 1 and Group 2 demonstrated a statistical significance of $F \mathrm{E}_{\mathrm{NO}}(p<0.05)$ but not of PEF $(p>0.05)$ (Figure 3 A,B).

\section{Comparison of subjective symptoms of study subjects after mask use}

Subjective symptoms reporting after wearing the mask found that the LDC mask was more comfortable to wear. In Group 1, study subjects who wore the LMC mask, 79.4\% reported the beneficial effect with clearer nasal passageways. For those who wore the conventional mask (Group 2), $6.1 \%$ reported clearer nasal passageways (Table 4). In Group 1, 8.8\% reported sneezing or stuffy nose and 2.9\% reported itchy throat (Table 4). In Group 2, 15.2\% reported sneezing, stuffy nose or runny nose; $6.1 \%$ in Group 2 reported sore throat, $15.1 \%$ reported cough after wearing conven- tional mask and 3.0\% reported difficulty breathing (Table 4 and Figure 4). There was a significant difference between Group 1 and Group 2 for respiratory and throat symptoms after mask use $(p<0.05$ and $\mathrm{p}<0.05$, respectively; Table 4 and Figure 4$)$.

Table 3. Comparison of modifications of PEF and $F E_{\mathrm{NO}}$ after mask use between Group 1 and 2.

\begin{tabular}{lccc} 
Parameters & Before mask use After mask use & $\boldsymbol{p}$ \\
Peak flow (L/min) & & \\
Group 1 ( $\mathrm{n}=34)$ & $430.3 \pm 85.2$ & $435.5 \pm 76.9$ & NS \\
Group 2 (n=33) & $433 \pm 99.1$ & $428.2 \pm 104.6$ & NS \\
$\boldsymbol{F E}_{\mathrm{No}}$ (ppb) & & & \\
Group 1 ( $=34)$ & $13.2 \pm 6.5$ & $8.2 \pm 4.2$ & 0.01 \\
Group 2 (n=33) & $11.8 \pm 7.0$ & $12.3 \pm 7.4$ & NS \\
\hline
\end{tabular}

PEF, peak expiratory flow; $F \mathrm{E}_{\mathrm{N} 0}$, fractional concentration of nitric oxide in exhaled breath; ppb, part per billion. Group 1, LMC mask use; Group 2, conventional mask use.
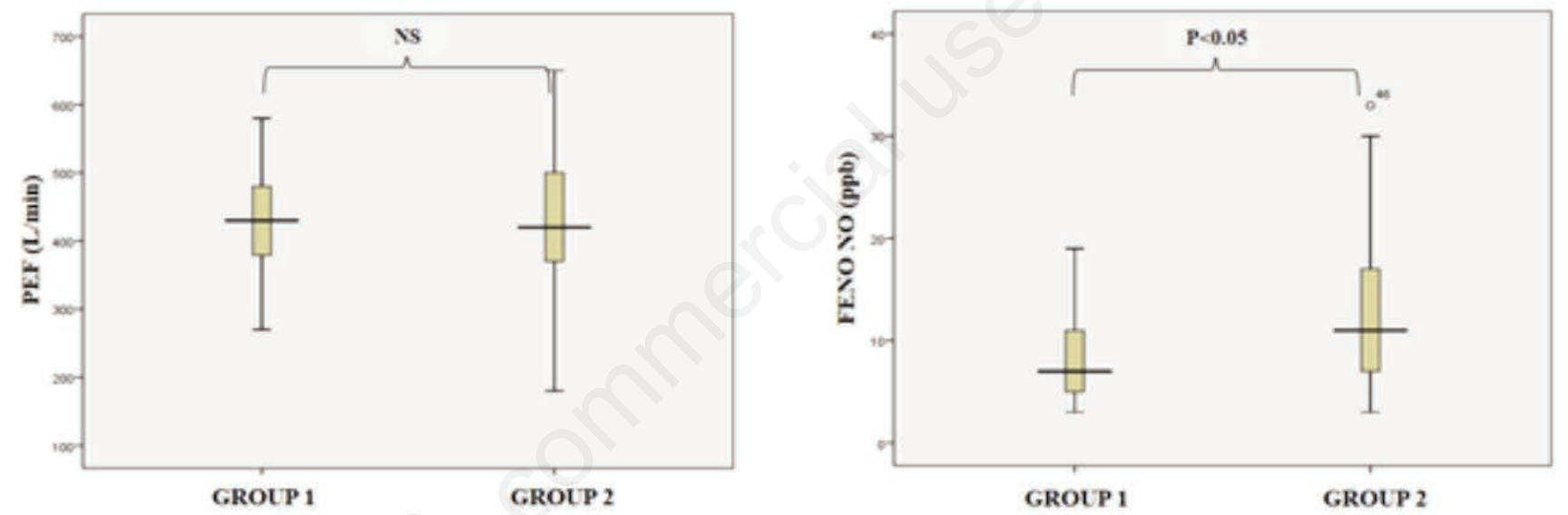

Figure 3. Comparison of PEF and $F \mathrm{E}_{\mathrm{NO}}$ between Group 1 and Group 2 after mask use. PEF, peak expiratory flow; $F \mathrm{E}_{\mathrm{NO}}$, fractional concentration of nitric oxide in exhaled breath; ppb, part per billion; Group 1, LMC mask use; Group 2, conventional mask use.

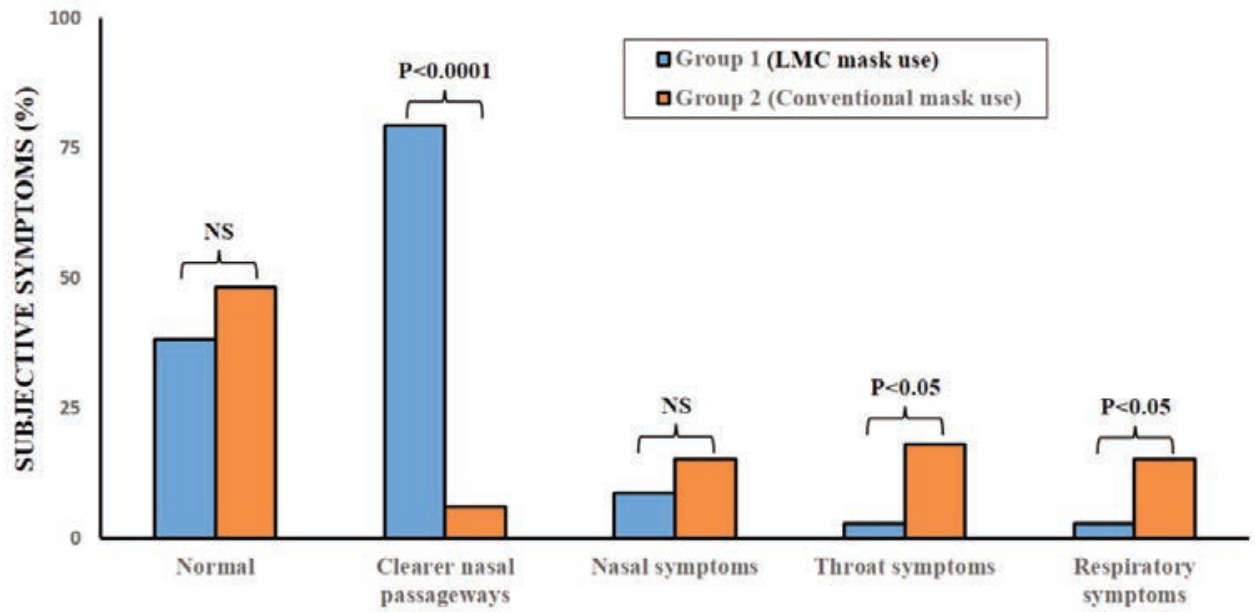

Figure 4. Comparison of subjective symptoms of study subjects after mask use. 


\section{Biological activity testing}

To confirm the sterilization of brand new masks (LMC and conventional masks), five new masks in each Group were chosen randomly for bacterial culture. The results showed clear (sterile) rings for both masks $(100 \% ; \mathrm{n}=5)$ with no significant difference of mean radius $(1.0 \pm 0.2$ vs $0.8 \pm 0.3 \mathrm{~cm}$, respectively; $p>0.05)$, confirming both masks were resistant to bacteria. For aerobic microbial testing, on the disc implant of the mask of Group 1, there appeared a sterile ring with a radius of $0.5 \pm 0.2 \mathrm{~cm}$ in $100 \%$ mask cultured pieces $(n=15)$. On the mask of Group 2, there appeared bacteria in $100 \%$ of mask cultured pieces (not identified; $n=15$ ). Antibacterial ability of masks of Group 1 appears better than Group 2, suggesting improved aerobic bacterial resistance in the LMC mask.

\section{Discussion}

This study suggests that the LMC face mask is equal in effectiveness and perhaps superior compared to internationally sold surgical face masks. Furthermore, the study demonstrates that utilizing local resources to manufacture face masks may be a feasible alternative to purchasing international face masks, especially during a COVID-19 pandemic when resources are scarce. Oil from Folium Plectranthii amboinicii (Lour.) Speng was found to be an effective antimicrobial when tested and it may be an effective addition to the production of face masks. Furthermore, the decrease in $F \mathrm{E}_{\mathrm{NO}}$ (Figure 3) demonstrated that the antimicrobial component of LMC mask including extracts from Folium Plectranthii amboinicii (Lour.) Speng, activated carbon and BSI solution did not produce the bronchial allergic response that usually is manifested by increased $F \mathrm{E}_{\mathrm{NO}}$ and might be due to the improvement of comfortability with breathing (Table 4 and Figure 4). However, the levels of $F \mathrm{E}_{\mathrm{NO}}$ before and after the use of $\mathrm{LMC}$ masks were still in normal range. In this study, $F \mathrm{E}_{\mathrm{NO}}$ was used to evaluate the effect of active carbon associated with BSI solution and Folium Plectranthii amboinicii (Lour.) Speng oil extract on the airways. Interestingly, the level of $F \mathrm{E}_{\mathrm{NO}}$ after LMC mask use was significantly lower than that measured before LMC mask use (Table 3). This result suggests LMC mask do not have an allergic effect on the airways of users because this effect usually increase $F \mathrm{E}_{\mathrm{NO}}$ level. The positive results of subjective comfortability also demonstrated the beneficial effects of LMC mask use that might explain another possible reason for the drop in $F \mathrm{E}_{\mathrm{NO}}$ after mask using would be the good breathing during mask wearing; thus, with our LMC mask, comfort was greater and tolerance better suggesting that hyperventilation unlikely accounted for the drop in $F \mathrm{E}_{\mathrm{NO}}$. Face masks are an integral component of infection prevention in the healthcare setting. The effectiveness of a mask in preventing inhalation of pollutants and pathogens is dependent on the intrinsic ability of the mask to withstand penetration of airborne particles [16]. N95 respirators have a filtering capacity of at least $95 \%$ of the challenge aerosol, whereas conventional masks have a filtering capacity of $10 \%$ to less than $90 \%$ [17-19]. The manufactured mask of this study (LMC face mask), made of 5 layers of heat seal filter paper, combined with two blotting paper in the medium which have been covered by activated carbon, BSI solution and Folium Plectranthii amboinicii oil extract, has a high performance of filter capacity after seal heating, and can be used to replace traditional surgical masks, but more data are necessary before it can replace N95 or greater masks. However, N95 and greater masks that are not properly fitted and do not seal, do not have the same efficacy compared to fitted masks that form a seal making proper fitting an integral part of using N95 masks [3]. Without proper fitting they may not be any more effective than LMC mask.

In the present study, the LMC face mask was found to have reduced upper airway symptoms and irritation, and may be a more comfortable alternative to conventional face masks. The subjective reporting of reduced upper airway symptoms and irritation is supported by $F \mathrm{E}_{\mathrm{NO}}$ measurement after use, a biomarker of airway inflammation and hyper-reactivity [13]. The $F \mathrm{E}_{\mathrm{NO}}$ of subjects wearing the $\mathrm{LMC}$ face mask was improved in comparison to those wearing the conventional face mask but the levels of $F \mathrm{E}_{\mathrm{NO}}$ in both groups of study subjects were still in normal range for adults (Table 3 and Figure 3). The drop of $F \mathrm{E}_{\mathrm{NO}}$ after using LMC masks suggests that the paper masks with oil from Plectranthii amboinicii may be more comfortable for people to wear the face mask. $F \mathrm{E}_{\mathrm{NO}}$ has been known as a biomarker of airway inflammation and used in diagnosis of airway hypersensitivity, mainly in asthma [13,20]. The normal level of $F \mathrm{E}_{\mathrm{NO}}$ measured after wearing the LMC mask suggests that LMC mask did not have any allergic or inflammatory effect on the airways due to the use of mask.

In addition, this study found that the LMC face mask may have equal filtering capacity to internationally sold conventional surgical and medical masks. A recent study on homemade face masks demonstrated that conventional surgical and medical masks were three times more effective in reducing microorganism

Table 4. Comparison of subjective symptoms of study subjects after mask use.

\begin{tabular}{|c|c|c|c|}
\hline Parameters & Group $1(n=34)$ & Group $2(n=33)$ & $p$ \\
\hline Normal, \% & $38.2(13)$ & $48.4(16)$ & NS \\
\hline $\begin{array}{l}\text { Favorable effect } \\
\text { Clearer nasal passageways, } \%\end{array}$ & 79.4 (27) & $6.1(2)$ & $<0.0001$ \\
\hline $\begin{array}{l}\text { Side effect } \\
\text { Nasal symptoms, \% } \\
\text { Sneezing, \% } \\
\text { Stuffy nose, \% } \\
\text { Runny nose, \% }\end{array}$ & $\begin{array}{l}8.8(3) \\
5.9(2) \\
2.9(1) \\
0.0(0)\end{array}$ & $\begin{array}{l}15.2(5) \\
6.1(2) \\
6.1(2) \\
3.0(1)\end{array}$ & $\begin{array}{l}\text { NS } \\
\text { NS } \\
\text { NS } \\
\text { NS }\end{array}$ \\
\hline $\begin{array}{l}\text { Throat symptoms, } \% \\
\text { Itchy throat, } \% \\
\text { Sore throat, } \%\end{array}$ & $\begin{array}{l}2.9(1) \\
2.9(1) \\
0.0(0)\end{array}$ & $\begin{array}{l}18.2(6) \\
12.1(4) \\
6.1(2)\end{array}$ & $\begin{array}{l}0.020 \\
\text { NS } \\
\text { NS }\end{array}$ \\
\hline $\begin{array}{l}\text { Respiratory symptoms, } \% \\
\text { Cough, } \% \\
\text { Difficulty breathing, } \%\end{array}$ & $\begin{array}{l}2.9(1) \\
2.9(1) \\
0.0(0)\end{array}$ & $\begin{array}{l}18.2(6) \\
15.2(5) \\
3.0(1)\end{array}$ & $\begin{array}{l}0.020 \\
0.009 \\
\text { NS }\end{array}$ \\
\hline
\end{tabular}

Group 1, LMC mask use; Group 2, conventional mask use. 
transmission compared to homemade masks [21]. The current study suggests that the LMC face mask may be equal in effectiveness to preventing airborne infections when compared to conventional masks. In fact, our previous studies demonstrated that oil extracted from Folium Plectranthii amboinicii (Lour.) Speng has antimicrobial and anti-inflammatory activity. The present study utilized the antimicrobial capacity of the oil from Plectranthii amboinicii and showed reduced bacterial and fungal growth on the LMC mask compared to the conventional mask. The LMC mask appears to have equal filtering capacity to conventional masks, but also has an improved antibacterial one secondary to the oil from Folium Plectranthii amboinicii (Lour.) Speng.

Because the LMC face mask was manufactured using local available materials, the study implies that in the setting of a COVID-19 pandemic, healthcare material suppliers could manufacture their own face masks using locally sourced materials [22]. This would improve the supply of medical masks in the community during a shortage of mask due to COVID-19 pandemic. Seal heat filter paper and other locally sourced materials, rather than plastic, were used to manufacture the LMC face mask. The reduced reliance on plastic is more sustainable and cleaner for the environment, making it easier for individual countries to maintain an adequate supply of safe and renewable face masks during future pandemic. The patent requirement of LMC face mask has been submitted at National Office of Intellectual Property of Vietnam in March 2020.

The study does have some limitations. Subjects were recruited only from staff of local college. Thus, the results may not be generalizable to the general public and other demographic groups. Subjects were not exposed to pathogens while wearing the masks. Therefore, it is possible we may be overestimating the effectiveness of the mask. In addition, subjects were asked to provide binary answers to subjective questions on comfort and breathability while wearing the mask. Lastly, long term safety from inhalation exposure to the plant oil, such as lipoid pneumonia, cannot be excluded, but none of the recruited subjects demonstrated signs or symptoms from the use of the mask over the following weeks. Nonetheless, our results suggest using high quality of filter paper to make masks during the pandemic-induced mask shortage can be successful. LMC mask provided easier breathability, less airway inflammation demonstrated by improved $F \mathrm{E}_{\mathrm{NO}}$ values, and equal efficacy as conventional masks. Despite the challenges, further investigation with a greater number of subjects should be performed to determine if oil from Folium Plectranthii amboinicii (Lour.) Speng can improve the function and breathability of face masks and be worn without any ill effects for extended periods of time.

\section{Conclusions}

Creating a medical face mask utilizing locally sourced materials as well as adding oil from Folium Plectranthii amboinicii (Lour.) Speng to improve antimicrobial capacity and breathability of the mask is possible. However, the study could not assess whether the LMC mask provides extended protection from pathogens, especially viral pathogens, as compared to N95, but appears to be ample in efficacy as traditionally used medical and surgical masks. Nonetheless, the study shows that face masks can be locally manufactured during an epidemic with a cleaner impact on the environment compared to conventional plastic-based face masks. Further research should be undertaken to determine if the addition of oil from Folium Plectranthii amboinicii (Lour.) Speng provides additional antimicrobial protection to conventional face masks.

\section{Acknowledgements}

The authors would like to thank all the Member of Clinical Research Centers of Lamdong Medical College for their contribution to this work.
Abbreviations
LMC:
NO:
Lam Dong Medical College; nitric oxide;
$F \mathrm{E}_{\mathrm{NO}}$ :
PEF:
BTH: fractional concentration of nitric oxide;
COPD: chronic obstructive pulmonary disease;
ppb: $\quad$ part per billion;
BMI: $\quad$ body mass index.

\section{References}

1. Zhou SS, Lukula S, Chiossone C, Nims RW, Suchmann DB, Ijaz MK. Assessment of a respiratory face mask for capturing air pollutants and pathogens including human influenza and rhinoviruses. J Thorac Dis 2018;10:2059-69.

2. Cowling BJ, Zhou Y, Ip DKM, Leung GM, Aiello AE. Face masks to prevent transmission of influenza virus: a systematic review. Epidemiol Infect 2010;138:449-56.

3. Smith JD, Macdougall CC, Johnstone J, Copes RA, Schwartz B, Garber GE. Effectiveness of N95 respirators versus surgical masks in protecting health care workers from acute respiratory infection: a systematic review and meta-analysis. CMAJ 2016;188:567-74.

4. Carias C, Rainisch G, Shankar M, Adhikari BB, Swerdlow DL, Bower WA, et al. Potential demand for respirators and surgical masks during a hypothetical influenza pandemic in the United States. Clin Infect Dis 2015;60:S42-51.

5. Truong-Thanh T, Tran Thi Minh T, Tang Thi Thao T, Tang Le Quynh T. Study the effect of Plectranthii amboinicii's tea in treatment of acute bronchitis. J Funct Vent Pulmonol 2019;10: 36-40.

6. Tang-Le-Quynh T, Ngo-Duy-Tuy H, Mai-Thanh K, TranThanh D, Tran-Ngoc T, Le-Quang K, et al. Study of active compounds of Plectranthii Amboinicii leaves growing in Dalat City, Vietnam and its antibacterial and antioxidant activities. World J Pharm Pharm Sci 2017;6:77-94.

7. Tiwari D, Nagar H, Dwivedi G, Tripathi R, Jena J. Evaluation of anti-anxiety activity of Plectranthus amboinicus (Lour.) on rats. Asian J Pharm Clin Res 2012;5:110-3.

8. Pillai PG, Suresh P, Aggarwal G, Doshi G, Bhatia V. Pharmacognostical standardization and toxicity profile of the methanolic leaf extract of Plectranthus amboinicus (Lour) Spreng. J Appl Pharm Sci 2011;1:76-81.

9. Manjamalai A, Alexander T, Berlin Grace VM. Bioactive evaluation of the essential oil of plectranthus amboinicus by GC-MS analysis and its role as a drug for microbial infections and inflammation. Int J Pharm Pharm Sci 2012;4:S205-11.

10. Selvakumar P, Naveena BE, Prakash SD. Studies on the antidandruff activity of the essential oil of coleus amboinicus and eucalyptus globulus. Asian Pacific J Trop Dis 2012;2: S715-9.

11. Galvão Rodrigues FF, Costa JGM, Rodrigues FFG, Campos AR. Study of the interference between plectranthus species essential oils from Brazil and aminoglycosides. Evid Based 
Complement Altern Med 2013;2013:724161.

12. Duong-Quy S. Clinical utility of the exhaled nitric oxide (NO) measurement with portable devices in the management of allergic airway inflammation and asthma. J Asthma Allergy 2019;12:331-41.

13. Dweik RA, Boggs PB, Erzurum SC, Irvin CG, Leigh MW, Lundberg JO, et al. An official ATS clinical practice guideline: interpretation of exhaled nitric oxide levels (FENO) for clinical applications. Am J Respir Crit Care Med 2011;184: 602-15.

14. Heffler E, Carpagnano GE, Favero E, Guida G, Maniscalco M, Motta A, et al. Fractional Exhaled Nitric Oxide (FENO) in the management of asthma: a position paper of the Italian Respiratory Society (SIP/IRS) and Italian Society of Allergy, Asthma and Clinical Immunology (SIAAIC). Multidiscip Respir Med 2020;15:36.

15. Tsurikisawa N, Oshikata C, Sato T, Kimura G, Mizuki M, Tsuburai $\mathrm{T}$, et al. Low variability in peak expiratory flow predicts successful inhaled corticosteroid step-down in adults with asthma. J Allergy Clin Immunol Pract 2018;6:972-9.

16. Eninger RM, Honda T, Adhikari A, Heinonen-Tanski H, Reponen T, Grinshpun SA. Filter performance of N99 and N95 facepiece respirators against viruses and ultrafine particles. Ann Occup Hyg 2008;52:385-96.

17. Grinshpun SA, Haruta H, Eninger RM, Reponen T, McKay RT,
Lee SA. Performance of an N95 filtering facepiece particulate respirator and a surgical mask during human breathing: Two pathways for particle penetration. J Occup Environ Hyg 2009; 6:593-603.

18. Lee S, Grinshpun SA, Reponen T. Respiratory performance offered by $\mathrm{N} 95$ respirators and surgical masks: Human subject evaluation with $\mathrm{NaCl}$ aerosol representing bacterial and viral particle size range. Ann Occup Hyg 2008;52:177-85.

19. Oberg T, Brosseau LM. Surgical mask filter and fit performance. Am J Infect Control 2008;36:276-82.

20. Dinh-Thi-Dieu H, Vo-Thi-Kim A, Tran-Van H, Tang-Thi-Thao T, Duong-Quy S. Study of the beneficial role of exhaled nitric oxide in combination with GINA guidelines for titration of inhaled corticosteroids in children with asthma. J Breath Res 2020;14:026014.

21. Davies A, Thompson KA, Giri K, Kafatos G, Walker J, Bennett A. Testing the efficacy of homemade masks: would they protect in an influenza pandemic? Disaster Med Public Health Prep 2013;7:413-8.

22. Wang X, Zhang X, He J. Challenges to the system of reserve medical supplies for public health emergencies: reflections on the outbreak of the severe acute respiratory syndrome coronavirus 2 (SARS-CoV-2) epidemic in China. Biosci Trends 2020;14:3-8.

Received for publication: 8 April 2020. Accepted for publication: 18 May 2020.

This work is licensed under a Creative Commons Attribution-NonCommercial 4.0 International License (CC BY-NC 4.0).

(C) Copyright: the Author(s), 2020

Licensee PAGEPress, Italy

Multidisciplinary Respiratory Medicine 2020; 15:664

doi:10.4081/mrm.2020.664 